Marquette University

e-Publications@Marquette

Biomedical Engineering Faculty Research and

Publications

Biomedical Engineering, Department of

$11-2017$

\title{
Robotic Resistance Treadmill Training Improves Locomotor Function in Children With Cerebral Palsy: A Randomized Controlled Pilot Study
}

\author{
Ming Wu \\ Rehabilitation Institute of Chicago \\ Janis Kim \\ Rehabilitation Institute of Chicago \\ Deborah J. Gaebler-Spira \\ Rehabilitation Institute of Chicago \\ Brian D. Schmit \\ Marquette University, brian.schmit@marquette.edu \\ Pooja Arora \\ Rehabilitation Institute of Chicago
}

Follow this and additional works at: https://epublications.marquette.edu/bioengin_fac

Part of the Biomedical Engineering and Bioengineering Commons

\section{Recommended Citation}

Wu, Ming; Kim, Janis; Gaebler-Spira, Deborah J.; Schmit, Brian D.; and Arora, Pooja, "Robotic Resistance Treadmill Training Improves Locomotor Function in Children With Cerebral Palsy: A Randomized Controlled Pilot Study" (2017). Biomedical Engineering Faculty Research and Publications. 527.

https://epublications.marquette.edu/bioengin_fac/527 
Marquette University

e-Publications@Marquette

\section{Biomedical Engineering Faculty Research and Publications/College of} Engineering

This paper is NOT THE PUBLISHED VERSION; but the author's final, peer-reviewed manuscript. The published version may be accessed by following the link in th citation below.

Archives of Physical Medicine and Rehabilitation, Vol. 98, No. 11 (November 2017): 2126-2133. DOI. This article is (C) the American Congress of Rehabilitation Medicine and permission has been granted for this version to appear in e-Publications@Marquette. the American Congress of Rehabilitation Medicine does not grant permission for this article to be further copied/distributed or hosted elsewhere without the express permission from the American Congress of Rehabilitation Medicine.

\section{Robotic Resistance Treadmill Training Improves Locomotor Function in Children With Cerebral Palsy: A Randomized Controlled Pilot Study}

\section{Ming Wu}

Sensory Motor Performance Program, Rehabilitation Institute of Chicago, Chicago, IL Northwestern University Medical School, Chicago, IL

Janis Kim

Sensory Motor Performance Program, Rehabilitation Institute of Chicago, Chicago, IL Deborah J. Gaebler-Spira

Sensory Motor Performance Program, Rehabilitation Institute of Chicago, Chicago, IL Brian D. Schmit

Sensory Motor Performance Program, Rehabilitation Institute of Chicago, Chicago, IL Northwestern University Medical School, Chicago, IL

Marquette University, Milwaukee, WI 


\section{Pooja Arora}

Sensory Motor Performance Program, Rehabilitation Institute of Chicago, Chicago, IL

\section{Abstract \\ Objective}

To determine whether applying controlled resistance forces to the legs during the swing phase of gait may improve the efficacy of treadmill training as compared with applying controlled assistance forces in children with cerebral palsy (CP).

Design

Randomized controlled study.

\section{Setting}

Research unit of a rehabilitation hospital.

\section{Participants}

Children with spastic $\mathrm{CP}$ ( $\mathrm{N}=23$; mean age, 10.6y; range, 6-14y; Gross Motor Function Classification

System levels, I-IV).

\section{Interventions}

Participants were randomly assigned to receive controlled assistance $(n=11)$ or resistance $(n=12)$ loads applied to the legs at the ankle. Participants underwent robotic treadmill training 3 times a week for 6 weeks (18 sessions). A controlled swing assistance/resistance load was applied to both legs starting from the toe-off to mid-swing phase of gait during training.

Main Outcome Measures

Outcome measures consisted of overground walking speed, 6-minute walk distance, and Gross Motor Function Measure scores and were assessed pre and post 6 weeks of training and 8 weeks after the end of training.

\section{Results}

After 6 weeks of treadmill training in participants from the resistance training group, fast walking speed and 6minute walk distance significantly improved ( $18 \%$ and $30 \%$ increases, respectively), and 6-minute walk distance was still significantly greater than that at baseline (35\% increase) 8 weeks after the end of training. In contrast, overground gait speed and 6-minute walk distance had no significant changes after robotic assistance training.

\section{Conclusions}

The results of the present study indicated that robotic resistance treadmill training is more effective than assistance training in improving locomotor function in children with CP.

\section{Keywords}

Cerebral palsy, Child, Locomotion, Rehabilitation

\section{List of abbreviations}

ANOVA analysis of variance

CP cerebral palsy

GMFCS Gross Motor Function Classification System

GMFM Gross Motor Function Measure

IQR interquartile range

RPE rating of perceived exertion 
Attaining walking ability is often an important functional goal for children with cerebral palsy (CP). Among the children who are diagnosed with CP, up to $90 \%$ of them have difficulty walking. 1 , 2 Reduced walking speed and endurance are 2 of the main functional problems. $\underline{3}, \underline{4}$ Ambulation plays a central role in normal bone development ${ }^{\underline{5}}$ and cardiopulmonary endurance, $\underline{6} \underline{7}$ and children who are able to ambulate are more accomplished in activities of daily living and social roles than children who use a wheelchair. ${ }^{8}$ The development of independent gait and efficiency of walking are often the focus of therapeutic interventions for children with CP.

The use of treadmill training has demonstrated improvement in walking capacity in some children with CP. $\underline{\underline{9}}, \underline{10}$ For instance, results have indicated improvements in gait speed, $\underline{\underline{9}} \underline{11}$ endurance, $\underline{\underline{9}}$ and the Gross Motor Function Classification System (GMFCS) measures.10, 12 However, although statistically significant improvements in walking capacity with treadmill training have been shown, it remains unclear whether therapeutic effects of such training are maximized, and further evidence is needed to support treadmill training in children with $\mathrm{CP} . \underline{13}$

The results of motor learning studies indicated that active training is more effective than passive training in improving the efficacy of motor training. $\stackrel{14}{*}$ Thus, we postulated that active engagement from children with CP might improve the efficacy of locomotor training. We proposed that applying a resistance force to leg swing may force them to be more actively involved because they need to generate additional joint torques to counteract the load. In addition, applying a resistance force to leg swing may produce a deviation in step kinematics, that is, increase the kinematic errors, which is supported by previous studies in individuals poststroke $\underline{15}, \underline{16}$ and humans with spinal cord injury. $\stackrel{17}{ }$ Error augmentation may accelerate motor learning during treadmill training, 18, 19, 20 resulting in improvement in the efficacy of locomotor training in children with CP.

In contrast, providing leg assistance force may facilitate leg swing, which imitates the way that physical therapist provides leg assistance during treadmill training, and improve locomotor function in children with CP through use-dependent motor learning mechanisms, $\underline{21}$ but it may reduce the level of active engagement of children with CP. To date, there are no randomized controlled studies that have directly compared leg resistance with assistance during treadmill training in children with CP. The purpose of this study was to assess functional changes after resistance versus assistance treadmill training in children with CP. We hypothesized that children with $\mathrm{CP}$ in both groups would show improvements in locomotor function, which was assessed using walking speed and 6-minute walk distance, although greater improvements were expected after resistance training than after assistance training.

\section{Methods}

\section{Participants}

Participants were recruited through the outpatient department of the Rehabilitation Institute of Chicago between October 5, 2011 and July 16, 2014. Specifically, 92 children were contacted through phone calls, 69 children were excluded, and 23 children (11 boys and 12 girls) with CP were recruited to participate in this study (fig 1). The mean age of participants was 10.6 years (range, 6-14y). Their GMFCS level ranged from I to IV (I, $n=1$; II, $\mathrm{n}=11 ; \mathrm{III}, \mathrm{n}=8 ; \mathrm{IV}, \mathrm{n}=3$ ). 


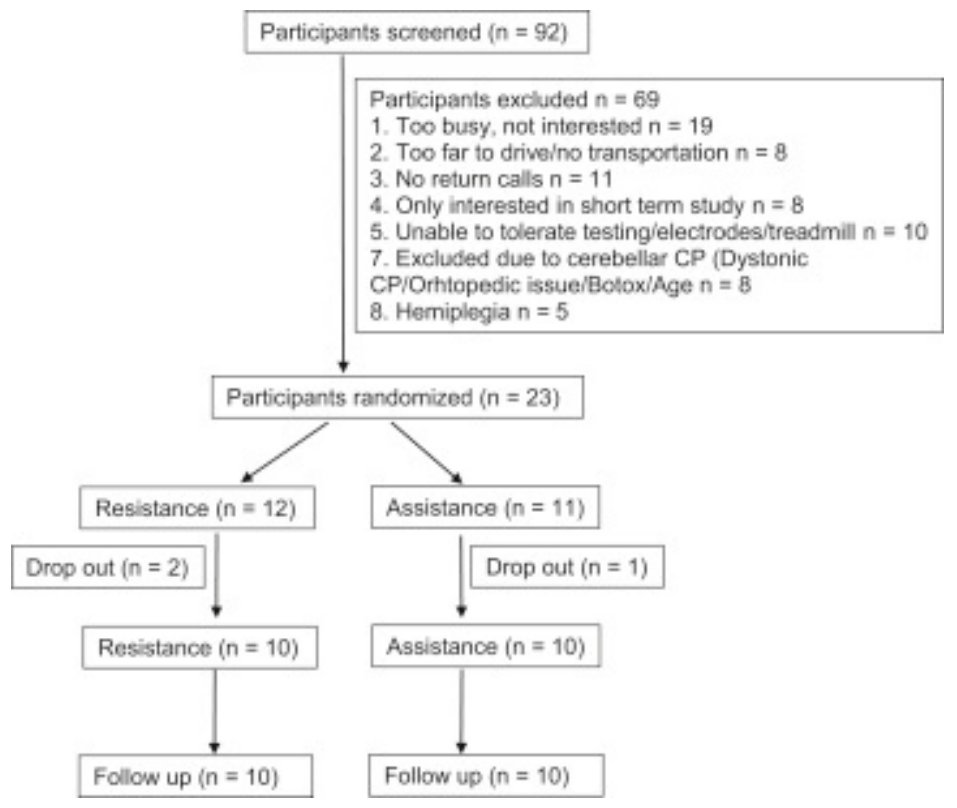

Fig 1. Flowchart of participants' enrollment and randomization.

Inclusion criteria included (1) a diagnosis of bilateral spastic CP attributed to complications of prematurity, intracranial hemorrhage, and periventricular leukomalacia according to the definition of Bax ${ }^{22}$; (2) aged 4 to 14 years; (3) without botulinum toxin treatment and orthopedic surgery or neurosurgery in the 6 months before the onset of training; (4) GMFCS level ranged from I to IV; (5) able to signal pain, fear, or discomfort reliably; (6) with mild scoliosis (Cobb angle $<20^{\circ}$ ); (7) passive range of motion within functional limits; and (8) able to follow instructions on behavior tests.

Exclusion criteria included severe lower extremity contractures, fractures, osseous instabilities, osteoporosis, severe disproportional bone growth, unhealed skin lesions in the lower extremities, thromboembolic diseases, cardiovascular instability, and aggressive or self-harming behaviors.

All procedures were approved by the Institutional Review Board of the Northwestern University. Medical clearance for participation was requested from the primary physician of each participant. Written consent was obtained from all participants and their parents.

\section{Apparatus}

A custom-designed cable-driven robotic gait training system was used to apply controlled resistance or assistance force to both legs during treadmill walking, which was reported previously. $\underline{23}$ In brief, the cable-driven robotic system consists of 4 direct current motors and cable spools (fig 2 ). Two motors and cable spools located in the front of the Woodway ${ }^{a}$ treadmill were used to apply a controlled assistance force to the legs at the ankle, and 2 motors located at the back of the treadmill were used to apply a resistance force to the legs. The ankle trajectory signals were measured using a custom-designed, 3-dimensional position detector. The ankle position signals were used by the operator to control the timing and magnitude of loading at targeted phases of gait. An adaptive control algorithm was used to automatically adjust the amount of the resistance/assistance load on the basis of the motor performance of the participants. $\underline{\underline{23}}$ The operator controlled the robotic system via a user interface that was programmed in LabVIEW. $\underline{\underline{b}}$ 


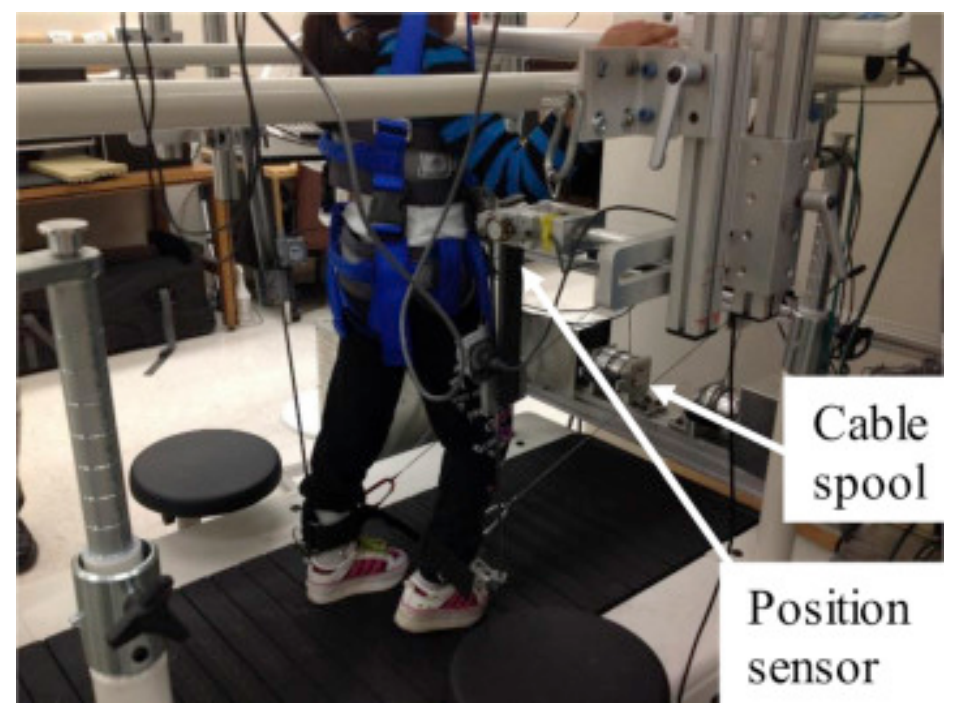

Fig 2. Experimental setup for the robotic assistance/resistance treadmill training. Two motors and cable spools are attached to a fixed frame located in front of the treadmill and are used to apply a controlled assistance force to the legs at the ankle, and 2 motors are attached to a frame located at the back of the treadmill and are used to apply a resistance force to the legs. A computer is used to control the coordinated movement of 4 motors.

\section{Protocol}

Participants were stratified according to initial gait speed and were randomly assigned to receive controlled assistance or resistance loads applied to both legs at the ankle. The treadmill speed was set at the comfortable speed of each participant on a treadmill, and an overhead harness was used to provide body weight support as needed to prevent knee buckling and toe drag. Participants walked on a treadmill for $\mathbf{4 0}$ minutes, which was adjusted on the basis of their tolerance on the activity, excluding setup time in each training session. Training sessions were conducted 3 times a week for 6 weeks. For participants who were assigned to the assistance training group, a load that assisted swing was applied to both legs starting from the toe-off to mid-swing phase of gait. For participants who were assigned to the resistance training group, a controlled resistance load was applied to both legs. Both the treadmill speed and the resistance/assistance load were gradually increased during the course of 6 weeks of treadmill training. Body weight support was provided in 8 participants ( 3 in the resistance group and 5 in the assistance group), with the average support being $11.4 \% \pm 4.2 \%$ of body weight at session 1 and $8.1 \% \pm 6.2 \%$ of body weight at session 18 . The rating of perceived exertion (RPE), $\underline{24}$ which was used to quantify the perceived training intensity, was monitored during the course of training, and the targeted RPE was 11 to 16 .

\section{Outcome measures}

Primary outcome measures included participant's self-selected and fast overground walking speed collected on a 10-m instrumented walkway (GAITRite $\left.{ }^{\mathrm{c}}\right) \underline{25}, \underline{26}$ and averaged across 3 trials, and walking distance assessed through the 6-minute timed walk. 27 Secondary outcome measures included clinical assessments of motor function. Specifically, dimensions D (standing) and $E$ (walking, running, jumping) of the Gross Motor Function Measure-66 (GMFM-66) were assessed by licensed physical therapists.28, 299 Physical function was measured using the Pediatric Outcomes Data Collection Instrument. $\underline{30}$ In addition, muscle tone of major knee joint muscle groups was assessed clinically with the Modified Ashworth Scale (score, $0-4), \underline{31}$ which was used before the GMFM and $\underline{\text { 6-minute walk tests. }}$ 


\section{Data analysis}

A power analysis was performed on the basis of the results of our previous pilot study, which indicated that with a power of 0.8 and an $\alpha$ of .05, 11 participants per group would be required. Baseline characteristics and training parameters were compared between the 2 test groups using paired $t$ tests and Wilcoxon rank-sum tests, as appropriate, and data normality was checked using the Shapiro-Wilk test. Repeated-measures analyses of variance (ANOVAs) were used for all parametric measures for within-group comparison. If a significant difference was detected, post hoc Tukey-Kramer tests were conducted to determine which conditions were different from each other. Modified Ashworth Scale scores were analyzed using Friedman tests with post hoc Wilcoxon tests. Changes in primary outcomes (ie, gait speed and endurance) were calculated by subtracting the baseline value from the values obtained at posttesting and follow-up testing and analyzed using repeatedmeasures ANOVA with main factor of treatment (resistance vs assistance training) and repeated for time (posttesting and follow-up testing). Statistical significance for all tests was set at $P<.05$.

\section{Results}

Twenty participants completed all the training and assessment sessions, with 3 participants dropping out (because of poor attendance, child's request, and participation in another study, respectively). At baseline, there were no significant differences between the 2 groups in age, overground walking speed, 6-minute walk distance, and GMFM scores (table 1). Treadmill training speed, distance, and time were gradually increased for both groups $(P<.01)$ during the course of training, with no significant difference noted between the 2 groups. In addition, the training intensity, which was quantified using RPE, had no significant difference between the 2 groups (table 2).

Table 1. Characteristics of the participants for baseline comparisons

\begin{tabular}{|l|l|l|l|}
\hline Characteristic & Resistance Training & Assistance Training & $P$ \\
\hline Age (y) & $10.6 \pm 3.0$ & $10.8 \pm 2.3$ & .93 \\
\hline Sex: male/female & $6 / 6$ & $5 / 6$ & NA \\
\hline Race: white/other & & & \\
\hline African American & 1 & 1 & NA \\
\hline Asian & 1 & 0 & NA \\
\hline Hispanic & 4 & 5 & NA \\
\hline White & 6 & 5 & NA \\
\hline Extremity distribution & & & \\
\hline Diplegia & 7 & 7 & NA \\
\hline Quadriplegia & 5 & 4 & NA \\
\hline GMFCS level & & & NA \\
\hline I & 1 & 0 & NA \\
\hline II & 5 & 5 & NA \\
\hline III & 5 & 4 & NA \\
\hline IV & 1 & 2 & \\
\hline Ankle braces & & & NA \\
\hline None & 0 & 2 & NA \\
\hline BAFO/SMO & 12 & 9 & \\
\hline GMFM score & & & .33 \\
\hline Total score & $63.6 \pm 8.6$ & $60.8 \pm 9.1$ & .18 \\
\hline Dimension D & $25.8 \pm 8.0$ & $22.8 \pm 11.3$ & .64 \\
\hline Dimension E & $32.3 \pm 18.2$ & $30.4 \pm 18.0$ & \\
\hline
\end{tabular}




\begin{tabular}{|l|l|l|l|}
\hline Self-selected walking speed $(\mathrm{m} / \mathrm{s})$ & $0.64 \pm 0.28$ & $0.57 \pm 0.23$ & .35 \\
\hline Fast walking speed $(\mathrm{m} / \mathrm{s})$ & $1.00 \pm 0.35$ & $0.88 \pm 0.34$ & .28 \\
\hline 6-min walk distance $(\mathrm{m})$ & $277.2 \pm 111.9$ & $228.3 \pm 117.8$ & .27 \\
\hline MAS score & $0.67 \pm 0.53$ & $0.95 \pm 0.72$ & .40 \\
\hline
\end{tabular}

NOTE. Values are mean \pm SD or $n$. $t$ tests and Wilcoxon rank-sum tests were used for comparison between the 2 groups.

Abbreviations: BAFO, bilateral ankle foot orthosis; MAS, Modified Ashworth Scale; NA, not applicable; SMO, supramalleolar orthosis.

Table 2. Training paradigms including treadmill speed, time, and training intensity at sessions 1, 9, and 18 for robotic resistance vs assistance treadmill training groups

\begin{tabular}{|l|l|l|l|}
\hline Variable & Resistance Training & Assistance Training & $\boldsymbol{P}$ \\
\hline Session 1 & & & \\
\hline Speed (m/s) & $0.42 \pm 0.15$ & $0.42 \pm 0.19$ & .95 \\
\hline Distance (km) & $0.80 \pm 0.31$ & $0.85 \pm 0.43$ & .78 \\
\hline Time (min) & $31 \pm 2$ & $33 \pm 3$ & .15 \\
\hline RPE & $12.9 \pm 2.9$ & $11.8 \pm 1.6$ & .27 \\
\hline Peak force (N) & $11.4 \pm 2.6$ & $13.2 \pm 2.9$ & .18 \\
\hline Session 9 & & & \\
\hline Speed (m/s) & $0.51 \pm 0.19$ & $0.49 \pm 0.16$ & .85 \\
\hline Distance (km) & $1.13 \pm 0.48$ & $1.11 \pm 0.45$ & .95 \\
\hline Time (min) & $36 \pm 3$ & $37 \pm 4$ & .58 \\
\hline RPE & $11.1 \pm 1.1$ & $12.2 \pm 1.6$ & .23 \\
\hline Peak force (N) & $13.3 \pm 4.1$ & $16.4 \pm 2.2$ & .08 \\
\hline Session 18 & & & \\
\hline Speed (m/s) & $0.53 \pm 0.22$ & .86 \\
\hline Distance (km) & $1.13 \pm 0.42$ & $1.28 \pm 0.57$ & .98 \\
\hline Time (min) & $39 \pm 3$ & $39 \pm 3$ & .93 \\
\hline RPE & $12.0 \pm 1.8$ & $11.3 \pm 1.5$ & .19 \\
\hline Peak force (N) & $14.8 \pm 5.2$ & $18.2 \pm 3.2$ & .15 \\
\hline
\end{tabular}

NOTE. Values are mean \pm SD. $t$ tests were used for comparison between the 2 groups.

Robotic resistance treadmill training improved walking function in children with CP. Specifically, fast walking speed significantly increased after robotic resistance treadmill training $\left(F_{2,9}=4.12\right.$; ANOVA, $\left.P=.03\right)$ (fig 3$)$. Post hoc tests indicated a significant increase from baseline to posttesting (mean increase, 18\%; interquartile range [IQR], $2 \%-31 \% ; P=.01$ ), although there was no significant difference between baseline and follow-up testing (increase, $17 \% ;$ IQR, $-6 \%$ to $17 \% ; P=.13$ ). Self-selected walking speed tended to increase (mean increase, $32 \%$; IQR, $-8 \%$ to $44 \%)$, but this was not significant because of large variability across participants $\left(F_{2,9}=1.66 ; P=.21\right)$. In addition, $6-$ minute walk distance significantly increased after resistance training $\left(F_{2,9}=10.04 ; P=.001\right)$. Post hoc tests indicated a significant increase from baseline to posttesting (increase, 30\%; IQR, 4\%-45\%; $P=.01$ ) and from baseline to follow-up testing (increase, 35\%; IQR, 6\%-64\%; $P=.001$ ). 
A

Fast speed

Self-selected speed

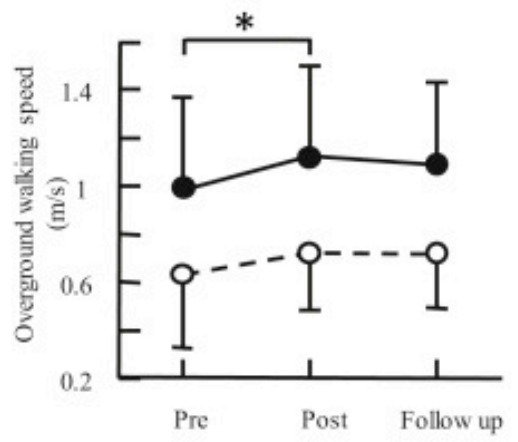

B

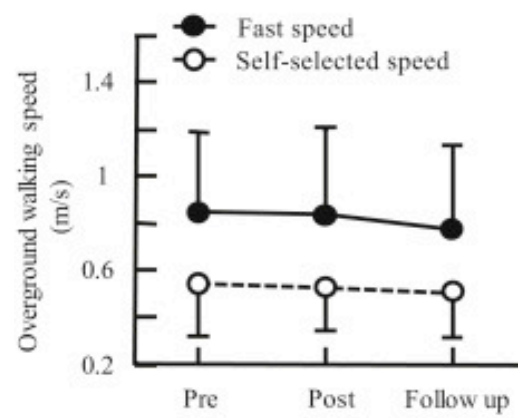

C

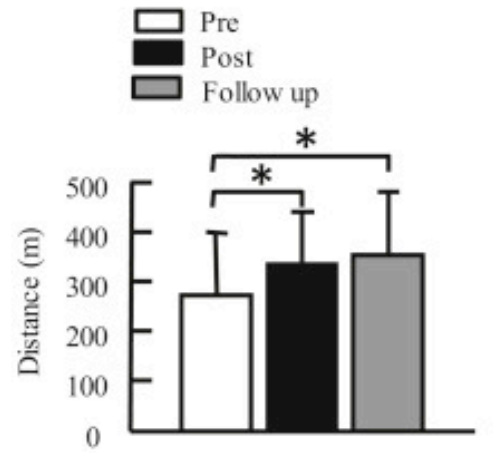

D

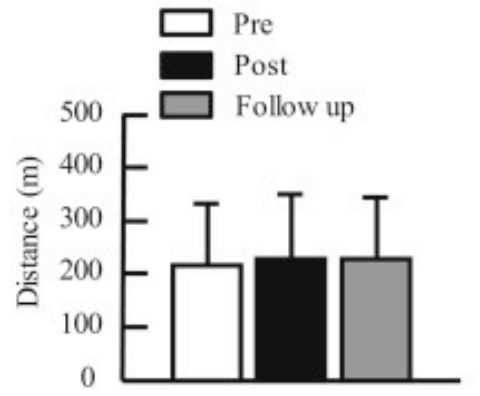

Fig 3. Average of self-selected walking speed, fast walking speed, 6-minute walk distance pre and post 6 weeks of robotic treadmill training and 8 weeks after the end of treadmill training, that is, follow-up testing. (A) 
Overground walking speed for participants from the resistance treadmill training group. (B) Overground walking speed for participants from the assistance treadmill training group. (C) Six-minute walk distance for participants from the resistance training group. (D) Six-minute walk distance for participants from the assistance training group. Three trials were conducted for walking speed and averaged across participants for each group. Error bars indicate SD of each gait parameter. *Significant difference, $P<.05$.

In contrast, robotic assistance treadmill training induced modest changes in walking function in children with CP. Specifically, both fast and self-selected walking speeds had no significant changes after assistance training (mean increase, $0.4 \%, I Q R, 0 \%-10 \% ; F_{2,9}=1.85 ; P=.19$ and increase, $2 \%, I Q R,-12 \%$ to $20 \% ; F_{2,9}=.51 ; P=.6$ for fast and self-selected walking speeds, respectively) (see fig 3 ). In addition, 6-minute walk distance had no significant change after assistance training (increase, $4 \%$; IQR, $-6 \%$ to $16 \% ; F_{2,9}=.48 ; P=.63$ ).

Greater functional gains were observed for participants who underwent resistance training than for those who underwent assistance training. Specifically, changes in self-selected walking speed, fast walking speed, and 6minute walk distance after treadmill training were significantly greater for participants from the resistance group than for participants from the assistance group $\left(F_{1,1}=5.36, P=.03 ; F_{1,1}=10 ; P=.003 ;\right.$ and $F_{1,1}=12.23 ; P=.001$ for self-selected walking speed, fast walking speed, and 6-minute walk distance, respectively) (fig 4). We observed no significant differences in changes in walking function between posttesting and follow-up testing ( $P=.75$ for self-selected walking speed, $P=.33$ for fast walking speed, and $P=.73$ for 6 -minute walk distance). GMFM scores significantly changed after resistance training $\left(F_{2,9}=5.21 ; P=.02\right)$. Post hoc tests indicated significant differences between posttesting and follow-up testing scores $(P=.02)$, although there was no significant difference between pretesting versus posttesting scores $(P=.89)$ and between pretesting and followup testing scores $(P=.05)$. In contrast, GMFM scores had no significant changes after assistance training $\left(F_{2,9}=.49 ; P=.69\right)$ (table 3$)$. In addition, step cadence during fast walking significantly increased after resistance training $\left(F_{2,9}=6.11 ; P=.01\right)$. Post hoc tests indicated significant differences in step cadence between pretraining and posttraining $(P=.01)$, although there was no significant difference between pretesting and follow-up testing $(P=.06)$ (table 4). Other spatial-temporal gait parameters had no significant changes for both groups $(P>.05)$. 


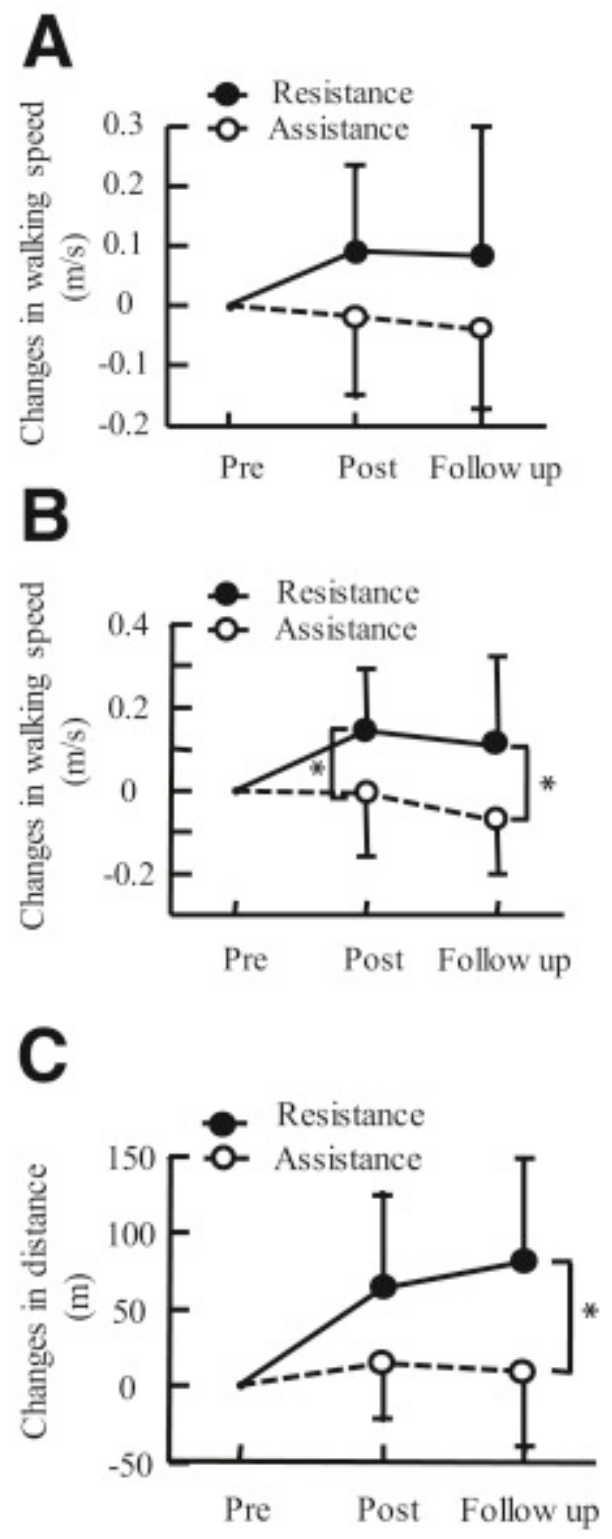

Fig 4. Changes in (A) self-selected walking speed, (B) fast walking speed, and (C) 6-minute walk distance after robotic resistance/assistance treadmill training and 8 weeks after the end of training, that is, follow-up testing. Data shown in the figure are the mean and SD of walking speeds and distance across participants. *Significant difference, $P<.05$.

Table 3. Self-selected walking speed, fast walking speed, and 6-minute walk distance, GMFM scores, MAS scores, and $\mathrm{PODCl}$ scores after robotic resistance and assistance treadmill training

\begin{tabular}{|l|l|l|l|l|l|l|l|l|}
\hline Variable & $\begin{array}{l}\text { Resistance } \\
\text { Training }\end{array}$ & Pre & Post & Follow-Up & $\boldsymbol{P}$ & $\begin{array}{l}\text { Pssistance } \\
\text { Training }\end{array}$ & & \\
\hline $\begin{array}{l}\text { Fast speed } \\
(\mathrm{m} / \mathrm{s})\end{array}$ & $0.98 \pm 0.39$ & $1.13 \pm 0.38$ & $1.09 \pm 0.35$ & $.01 \pm$ & $0.84 \pm 0.34$ & $0.84 \pm 0.37$ & $0.77 \pm 0.36$ & .19 \\
\hline $\begin{array}{l}\text { Self- } \\
\text { selected } \\
\text { speed } \\
(\mathrm{m} / \mathrm{s})\end{array}$ & $0.63 \pm 0.30$ & $0.72 \pm 0.24$ & $0.71 \pm 0.22$ & .22 & $0.54 \pm 0.22$ & $0.52 \pm 0.18$ & $0.50 \pm 0.19$ & .61 \\
\hline
\end{tabular}




\begin{tabular}{|l|l|l|l|l|l|l|l|l|}
\hline $\begin{array}{l}\text { 6minWD } \\
(\mathrm{m})\end{array}$ & $\begin{array}{l}272.7 \pm 113 . \\
0\end{array}$ & $\begin{array}{l}336.3 \pm 104 . \\
9\end{array}$ & $\begin{array}{l}353.9 \pm 125 . \\
8\end{array}$ & $.001 *$ & $\begin{array}{l}216.3 \pm 116 . \\
8\end{array}$ & $\begin{array}{l}230.1 \pm 119 \\
.2\end{array}$ & $\begin{array}{l}224.7 \pm 118 . \\
7\end{array}$ & .63 \\
\hline $\begin{array}{l}\text { GMFM } \\
\text { score }\end{array}$ & $63.7 \pm 8.7$ & $63.4 \pm 8.2$ & $64.9 \pm 9.4$ & $.02 *$ & $60.0 \pm 9.2$ & $59.8 \pm 9.6$ & $60.3 \pm 9.4$ & .69 \\
\hline $\begin{array}{l}\text { Total } \\
\text { score }\end{array}$ & $25.1 \pm 8.6$ & $26.0 \pm 6.9$ & $27.3 \pm 7.1$ & .18 & $21.7 \pm 11.3$ & $21.8 \pm 11.7$ & $20.8 \pm 11.4$ & .62 \\
\hline $\begin{array}{l}\text { Dimensio } \\
\mathrm{n} \text { D }\end{array}$ & $31.4 \pm 19.5$ & $30.5 \pm 19.2$ & $32.5 \pm 19.8$ & .11 & $29.2 \pm 18.5$ & $28.3 \pm 17.7$ & $28.8 \pm 19.5$ & .35 \\
\hline $\begin{array}{l}\text { Dimensio } \\
\mathrm{n} \text { E }\end{array}$ & $0.65 \pm 0.57$ & $0.83 \pm 0.66$ & $0.63 \pm 0.39$ & .97 & $0.85 \pm 0.67$ & $0.68 \pm 0.56$ & $0.87 \pm 0.55$ & .20 \\
\hline MAS score & $23.0 \pm 17.2$ & $23.0 \pm 18.0$ & $24.5 \pm 12.2$ & .84 & $23.0 \pm 23.6$ & $19.5 \pm 12.1$ & $24.0 \pm 16.0$ & .74 \\
\hline $\begin{array}{l}\text { PODCl } \\
\text { (self) } \\
\text { score }\end{array}$ & $7.5 \pm 16.2$ & $19.1 \pm 15.5$ & $19.0 \pm 16.8$ & $.002 *$ & $7.9 \pm 22.8$ & $9.8 \pm 16.4$ & $3.9 \pm 24.5$ & .83 \\
\hline $\begin{array}{l}\text { PODCl } \\
\text { (parent) } \\
\text { score }\end{array}$ & & & & & & & & \\
\hline
\end{tabular}

NOTE. Values are mean \pm SD. ANOVAs and Friedman tests were used for within-group comparison.

Abbreviations: 6minWD, 6-min walk distance; MAS, Modified Ashworth Scale; PODCl, Pediatric Outcomes Data Collection Instrument.

*Significant difference.

Table 4. Spatial-temporal gait parameters pre and post robotic resistance and assistance treadmill training

\begin{tabular}{|c|c|c|c|c|c|c|c|c|}
\hline Variable & \begin{tabular}{|l|} 
Resistance \\
Training \\
\end{tabular} & & & & $\begin{array}{l}\text { Assistance } \\
\text { Training }\end{array}$ & & & \\
\hline & Pre & Post & Follow-Up & $P$ & Pre & Post & Follow-Up & $P$ \\
\hline \multicolumn{9}{|l|}{ Fast walking } \\
\hline $\begin{array}{l}\text { Step length } \\
\text { (m) }\end{array}$ & $0.47 \pm 0.10$ & $0.50 \pm 0.09$ & $0.49 \pm 0.09$ & .26 & $0.42 \pm 0.10$ & $0.42 \pm 0.09$ & $0.40 \pm 0.10$ & .45 \\
\hline $\begin{array}{l}\text { Stride } \\
\text { length }(\mathrm{m})\end{array}$ & $0.94 \pm 0.20$ & $1.00 \pm 0.18$ & $0.98 \pm 0.18$ & .15 & $0.84 \pm 0.20$ & $0.84 \pm 0.18$ & $0.84 \pm 0.22$ & .99 \\
\hline $\begin{array}{l}\text { Cadence } \\
\text { (step/min) }\end{array}$ & $120.3 \pm 25.5$ & $136.5 \pm 29.0$ & $132.0 \pm 28.4$ & $.01 *$ & $119.2 \pm 40.2$ & $120.2 \pm 41.3$ & $116.9 \pm 44.3$ & .86 \\
\hline $\begin{array}{l}\text { Swing time } \\
(\%)\end{array}$ & $38.9 \pm 4.8$ & $39.8 \pm 3.8$ & $40.0 \pm 3.2$ & .61 & $40.1 \pm 5.6$ & $41.6 \pm 4.9$ & $40.6 \pm 7.2$ & .72 \\
\hline \multicolumn{9}{|l|}{$\begin{array}{l}\text { Normal } \\
\text { walking }\end{array}$} \\
\hline $\begin{array}{l}\text { Step length } \\
\text { (m) }\end{array}$ & $0.39 \pm 0.11$ & $0.43 \pm 0.09$ & $0.42 \pm 0.08$ & .16 & $0.34 \pm 0.09$ & $0.35 \pm 0.08$ & $0.35 \pm 0.08$ & .83 \\
\hline $\begin{array}{l}\text { Stride } \\
\text { length }(\mathrm{m})\end{array}$ & $0.78 \pm 0.22$ & $0.86 \pm 0.18$ & $0.85 \pm 0.16$ & .16 & $0.71 \pm 0.19$ & $0.71 \pm 0.16$ & $0.70 \pm 0.16$ & .98 \\
\hline $\begin{array}{l}\text { Cadence } \\
\text { (step/min) }\end{array}$ & $93.2 \pm 26.3$ & $100.6 \pm 21.8$ & $100.7 \pm 20.8$ & .22 & $91.4 \pm 27.8$ & $86.8 \pm 20.5$ & $83.9 \pm 23.8$ & .21 \\
\hline $\begin{array}{l}\text { Swing time } \\
\text { (\%) }\end{array}$ & $33.6 \pm 4.7$ & $35.7 \pm 1.9$ & $36.5 \pm 2.0$ & .11 & $36.1 \pm 4.8$ & $37.4 \pm 8.7$ & $38.2 \pm 7.7$ & .78 \\
\hline
\end{tabular}


NOTE. Values are mean \pm SD. ANOVAs were used for within-group comparison.

*Significant difference.

\section{Discussion}

Applying a controlled swing resistance force to the legs during robotic treadmill training induced significant improvements in walking function of children with CP. In contrast, applying an assistance force to legs during treadmill training induced only modest changes in walking function. Furthermore, greater functional gains in walking were obtained for participants from the resistance group than for those from the assistance group.

In this study, greater improvements in walking function were observed for children who underwent resistance training than for those who underwent assistance training. One possible reason for the differences in functional gains may be that children who underwent resistance training were more actively engaged in the locomotor training session than were those who underwent assistance training. Specifically, for children who were assigned the resistance training group, the resistance load applied to both legs during the swing phase may force participants to generate additional joint torque to counteract the load and move the leg forward during treadmill training, which may require participants to increase voluntary activation through enhanced supraspinal input to the motoneuron pool and/or increase motoneuron excitability. $\underline{32}$

In contrast, for children who underwent assistance training, the central nervous system may adapt to the assistance force applied to the leg(s) during the swing phase of gait by reducing the motor output of the leg $\underline{\text { muscles }}, \underline{33}$ probably owing to optimization of the energy cost. $\underline{34}$ Thus, a leg assistance force that is too large may encourage passive rather than active training. As a consequence, the training effect could be suboptimal. This is also consistent with a previous study, which indicated that only a modest increase in the gait speed of children with CP was observed after robotic training in which a passive guidance force was applied to both legs. $\frac{35}{H}$ However, the results of a previous study in adults with stroke indicated that assistance and resistance training induced comparable walking functional gains. $\underline{18}$ One possible reason may be due to the age (or the motivation level) difference of participants between the 2 studies.

In addition, the results of this study suggest that repeated exposure to force perturbations during walking may induce a prolonged retention of increased stride length in children with CP. The results of previous studies suggest that the neural system may adapt to the resistance force and show an aftereffect consisting of an increased stride length when the resistance force is removed (R. Tang et al, unpublished data, 2016), which is consistent with individuals poststroke $\underline{15}, \underline{36}$ and humans with spinal cord injury. $\underline{37}, \underline{38}$ Although the aftereffect after 1 session of swing resistance training is generally short-lived, the results of this study suggest that repeated exposure to a swing resistance force through long-term training, such as 18 sessions of training in this case, may induce an accumulation of increased stride length through a repeated adaptation and de-adaptation process, $\underline{\underline{39}}$ which is consistent with previous results of studies involving humans with spinal cord injury $\underline{19}$ and individuals poststroke using a split-belt paradigm. $\underline{20}$ In addition, repeated exposure to leg resistance force may enhance muscle activation of hip flexors, which may facilitate leg swing, but may have a modest effect on hip abductors, which are identified as key muscles in maintaining mediolateral balance of standing leg during walking. .00 As a result, we observed a greater increase in cadence but a smaller increase in step length because of modest change in single leg support time after resistance training.

To our knowledge, this is the first study to show the differences in walking functional gains in children with CP after robotic treadmill training with robotic resistance force versus assistance force. The functional gains obtained after robotic resistance treadmill training are comparable with, or even greater than, those obtained from previous studies using treadmill training. For instance, the functional gain in walking speed (ie, $.15 \mathrm{~m} / \mathrm{s}$, although $<.17 \mathrm{~m} / \mathrm{s}$, minimal clinically important difference) $)^{41}$ obtained after robotic resistance training was 
comparable with, or greater than, that obtained after treadmill training with applied manual assistance force $(.01-.07 \mathrm{~m} / \mathrm{s}) \underline{9}, \underline{42}$ or with robotic assistance force using the pediatric Lokomat $\underline{\underline{d}}$ (ie, $.02 \mathrm{~m} / \mathrm{s}), \underline{35}$ which is comparable with functional gains obtained after assistance training (ie, $-.02 \mathrm{~m} / \mathrm{s}$ ) and after robotic training using the GaitTrainer- (ie, $.12 \mathrm{~m} / \mathrm{s}$ ). ${ }^{43}$ Similarly, the functional gain in 6 -minute walk distance obtained after resistance training (i.e., $81.2 \mathrm{~m}$, which is greater than minimal clinically important difference, i.e., $61.5 \mathrm{~m}$ ) was greater than that obtained after treadmill training with manual assistance (ie, -25.0 to $-19.8 \mathrm{~m}), \underline{9}, \underline{42}$ which is comparable with functional gains obtained after assistance training (ie, $13.9 \mathrm{~m})$ and after robotic training using the GaitTrainer (ie, 69m). $\underline{4}$

The results of this study may have some clinical applications for improving locomotor function in children with $\mathrm{CP}$. For instance, to improve the efficacy of locomotor training, physical therapists may consider applying a resistance force to the legs and refrain from applying a manual assistance force (that is too large) to legs during locomotor training to increase the intensity and/or active involvement of children with CP.

\title{
Study limitations
}

This study has several limitations. For instance, the sample size was small because of the challenges of participant recruitment. In addition, the assessing physical therapists were not blinded to the group assignment, which may have potentially biased the results. We do not know whether a robotic resistance treadmill training paradigm is more effective than a conventional treadmill training paradigm, and we also do not know whether the cognitive abilities of individuals had an effect on the results. In addition, the reliability of GAITRite data from some low functional children with CP was relatively low, $\underline{25}$ which might affect the results. We also do not know whether the level of resistance/assistance load applied in this paradigm is optimized. Further studies are needed to optimize this resistance training paradigm.

\section{Conclusions}

Applying a resistance force to the legs during robotic treadmill training is more effective than applying an assistance force in improving walking function in children with CP. This suggests that active involvement of children with CP during locomotor training is crucial for improving the efficacy of treadmill training. In addition, repeated exposure to force perturbations induces a prolonged retention of improved stride length in children with CP.

\section{Suppliers}
a. Woodway treadmills; WOODWAY USA, Inc.
b. LabVIEW; National Instruments.
c. GAITRite; CIR Systems Inc.
d. Lokomat; Hocoma Inc, USA.
e. Gait Trainer GT I; Reha-Stim, Berlin, Germany.

\section{Acknowledgments}

We thank Sheng-Che Yen, PT, $\underline{\mathrm{PhD}}$, and Feng Wei, PhD, for their assistance in data collection. We also thank Jill Landry, PT, for her comments and suggestions on this article.

\section{References}

\author{
1 P.O. Pharoah, T. Cooke, M.A. Johnson, R. King, L. Mutch Epidemiology of cerebral palsy in England and
} Scotland, 1984-9 Arch Dis Child Fetal Neonatal Ed, 79 (1998), pp. F21-F25 
2 J.L. Hutton, P.O. Pharoah Effects of cognitive, motor, and sensory disabilities on survival in cerebral palsy Arch Dis Child, 86 (2002), pp. 84-89

3 C.M. Duffy, A.E. Hill, A.P. Cosgrove, I.S. Corry, H.K. Graham Energy consumption in children with spina bifida and cerebral palsy: a comparative study Dev Med Child Neurol, 38 (1996), pp. 238-243

4 K.F. Bjornson, C. Zhou, R. Stevenson, D. Christakis, K. Song Walking activity patterns in youth with cerebral palsy and youth developing typically Disabil Rehabil, 36 (2014), pp. 1279-1284

$\underline{5}$ S. Wilmshurst, K. Ward, J.E. Adams, C.M. Langton, M.Z. Mughal Mobility status and bone density in cerebral palsy Arch Dis Child, 75 (1996), pp. 164-165

$\underline{6}$ L.Y. Chien, Y.H. Chou, Y.K. Ko, C.F. Lee Health-related quality of life among 3-4-year-old children born with very low birthweight J Adv Nurs, 56 (2006), pp. 9-16

7 H. Gorter, L. Holty, E.E. Rameckers, H.J. Elvers, R.A. Oostendorp Changes in endurance and walking ability through functional physical training in children with cerebral palsy Pediatr Phys Ther, 21 (2009), pp. 31-37

$\underline{8}$ C. Lepage, L. Noreau, P.M. Bernard Association between characteristics of locomotion and accomplishment of life habits in children with cerebral palsy Phys Ther, 78 (1998), pp. 458-469

$\underline{9}$ K.J. Dodd, S. Foley Partial body-weight-supported treadmill training can improve walking in children with cerebral palsy: a clinical controlled trial Dev Med Child Neurol, 49 (2007), pp. 101-105

10 M.R. Schindl, C. Forstner, H. Kern, S. Hesse Treadmill training with partial body weight support in nonambulatory patients with cerebral palsy Arch Phys Med Rehabil, 81 (2000), pp. 301-306

11 B. Provost, K. Dieruf, P.A. Burtner, et al. Endurance and gait in children with cerebral palsy after intensive body weight-supported treadmill training Pediatr Phys Ther, 19 (2007), pp. 2-10

12 R.J. Cherng, C.F. Liu, T.W. Lau, R.B. Hong Effect of treadmill training with body weight support on gait and gross motor function in children with spastic cerebral palsy Am J Phys Med Rehabil, 86 (2007), pp. 548555

13 D.L. Damiano, S.L. DeJong A systematic review of the effectiveness of treadmill training and body weight support in pediatric rehabilitation J Neurol Phys Ther, 33 (2009), pp. 27-44

14 M. Lotze, C. Braun, N. Birbaumer, S. Anders, L.G. Cohen Motor learning elicited by voluntary drive Brain, 126 (Pt 4) (2003), pp. 866-872

15 S.C. Yen, B.D. Schmit, M. Wu Using swing resistance and assistance to improve gait symmetry in individuals post-stroke Hum Mov Sci, 42 (2015), pp. 212-224

16 D.N. Savin, S.C. Tseng, J. Whitall, S.M. Morton Poststroke hemiparesis impairs the rate but not magnitude of adaptation of spatial and temporal locomotor features Neurorehabil Neural Repair, 27 (2013), pp. 2434

17 S.C. Yen, J.M. Landry, M. Wu Size of kinematic error affects retention of locomotor adaptation in human spinal cord injury J Rehabil Res Dev, 50 (2013), pp. 1187-1200

18 M. Wu, J.M. Landry, J. Kim, B.D. Schmit, S.C. Yen, J. Macdonald Robotic resistance/assistance training improves locomotor function in individuals poststroke: a randomized controlled study Arch Phys Med Rehabil, 95 (2014), pp. 799-806

19 M. Wu, J.M. Landry, J. Kim, et al. Repeat exposure to leg swing perturbations during treadmill training induces long-term retention of increased step length in human $\mathrm{SCl}$ : a pilot randomized controlled study Am J Phys Med Rehabil, 95 (2016), pp. 911-920

20 D.S. Reisman, H. McLean, J. Keller, K.A. Danks, A.J. Bastian Repeated split-belt treadmill training improves poststroke step length asymmetry Neurorehabil Neural Repair, 27 (2013), pp. 460-468

$\underline{21}$ L. Sawaki, C.W. Wu, A. Kaelin-Lang, L.G. Cohen Effects of somatosensory stimulation on use-dependent plasticity in chronic stroke Stroke, 37 (2006), pp. 246-247

$\underline{22}$ M. Bax, M. Goldstein, P. Rosenbaum, et al. Proposed definition and classification of cerebral palsy, April 2005 Dev Med Child Neurol, 47 (2005), pp. 571-576 
$\underline{23}$ M. Wu, T.G. Hornby, J.M. Landry, H. Rosth, B.D. Schmit A cable-driven locomotor training system for restoration of gait in human SCI Gait Posture, 33 (2011), pp. 256-260

24 G. Borg Perceived exertion as an indicator of somatic stress Scand J Rehabil Med, 2 (1970), pp. 92-98

25 J.V. Graser, C. Letsch, H.J. van Hedel Reliability of timed walking tests and temporo-spatial gait parameters in youths with neurological gait disorders BMC Neurol, 16 (2016), p. 15

$\underline{26}$ N. Chrysagis, E.K. Skordilis, D. Koutsouki Validity and clinical utility of functional assessments in children with cerebral palsy Arch Phys Med Rehabil, 95 (2014), pp. 369-374

$\underline{27}$ C. Andersson, L. Asztalos, E. Mattsson Six-minute walk test in adults with cerebral palsy: a study of reliability Clin Rehabil, 20 (2006), pp. 488-495

28 D.J. Russell, P.L. Rosenbaum, D.T. Cadman, C. Gowland, S. Hardy, S. Jarvis The Gross Motor Function Measure: a means to evaluate the effects of physical therapy Dev Med Child Neurol, 31 (1989), pp. 341-352

29 D.J. Russell, L.M. Avery, P.L. Rosenbaum, P.S. Raina, S.D. Walter, R.J. Palisano Improved scaling of the Gross Motor Function Measure for children with cerebral palsy: evidence of reliability and validity Phys Ther, 80 (2000), pp. 873-885

30 L.H. Daltroy, M.H. Liang, A.H. Fossel, M.J. Goldbeg The POSNA pediatric musculoskeletal functional health questionnaire: report on reliability, validity, and sensitivity to change. Pediatric Outcomes Instrument Development Group. Pediatric Orthopaedic Society of North America J Pediatr Orthop, 18 (1998), pp. 561-571

$\underline{31}$ R.W. Bohannon, M.B. Smith Interrater reliability of a Modified Ashworth Scale of muscle spasticity Phys Ther, 67 (1987), pp. 206-207

32 M.M. Ekblom Improvements in dynamic plantar flexor strength after resistance training are associated with increased voluntary activation and V-to-M ratio J Appl Physiol (1985), 109 (2010), pp. 19-26

33 M. Wu, J. Kim, P. Arora, D.J. Gaebler-Spira, Y. Zhang Kinematic and EMG responses to pelvis and leg assistance force during treadmill walking in children with cerebral palsy Neural Plast, 2016 (2016), p. 5020348

34 D.J. Reinkensmeyer, O. Akoner, D.P. Ferris, K.E. Gordon Slacking by the human motor system: computational models and implications for robotic orthoses Conf Proc IEEE Eng Med Biol Soc, 2009 (2009), pp. 21292132

35 M. Druzbicki, W. Rusek, S. Snela, et al. Functional effects of robotic-assisted locomotor treadmill thearapy in children with cerebral palsy J Rehabil Med, 45 (2013), pp. 358-363

36 D.N. Savin, S.M. Morton, J. Whitall Generalization of improved step length symmetry from treadmill to overground walking in persons with stroke and hemiparesis Clin Neurophysiol, 125 (2014), pp. 10121020

37 S.C. Yen, D.B. Schmit, J.M. Landry, H. Roth, M. Wu Locomotor adaptation to resistance during treadmill training transfers to overground walking in human SCI Exp Brain Res, 216 (2012), pp. 473-482

38 A. Houldin, K. Luttin, T. Lam Locomotor adaptations and aftereffects to resistance during walking in individuals with spinal cord injury J Neurophysiol, 106 (2011), pp. 247-258

39 D.S. Reisman, A.J. Bastian, S.M. Morton Neurophysiologic and rehabilitation insights from the split-belt and other locomotor adaptation paradigms Phys Ther, 90 (2010), pp. 187-195

40 C.D. MacKinnon, D.A. Winter Control of whole body balance in the frontal plane during human walking J Biomech, 26 (1993), pp. 633-644

$\underline{41}$ G. Norman The effectiveness and effects of effect sizes Adv Health Sci Educ Theory Pract, 8 (2003), pp. 183187

42 K.L. Willoughby, et al. Efficacy of partial body weight-supported treadmill training compared with overground walking practice for children with cerebral palsy: a randomized controlled trial Arch Phys Med Rehabil, 91 (2010), pp. 333-339 
$\underline{43}$ N. Smania, et al. Improved gait after repetitive locomotor training in children with cerebral palsy Am J Phys Med Rehabil, 90 (2011), pp. 137-149 